\title{
Which low-fusing porcelain glaze treatment technique is better to promote a vitreous surface on Y-TZP ceramic?
}

Jean Soares Miranda ${ }^{\mathrm{a}}$, Natália Veloso Malta ${ }^{\mathrm{b}}$, Ronaldo Luís Almeida de Carvalho ${ }^{\mathrm{c}}$, Rodrigo Othávio de Assunção e Souza ${ }^{d}$, João Paulo Barros Machado ${ }^{e}$, Fabíola Pessôa Pereira Leite ${ }^{f}$

\begin{abstract}
OBJECTIVE: To evaluated the influence of two types of low-fusing porcelain glaze application on the surface of a zirconia ceramics stabilized by yttrium (Y-TZP).

METHODS: Y-TZP specimens were divided into five groups $(n=5)$ according the surface treatments: control (CO), no treatment was performed; application of a thin low-fusing porcelain glass layer by the powder/liquid technique (GPL); GPL followed by $10 \%$ hydrofluoric acid (HF) etching (GPL-HF); glaze spray application (GS); GS followed by $10 \%$ HF etching (GS-HF). Roughness measurements contact angle, $x$-ray diffraction, energy-dispersive spectroscopy (EDS) and scanning electron microscope (SEM) analysis were performed.

RESULTS: ANOVA and Tukey tests revealed that GPL had significantly lower contact angle values

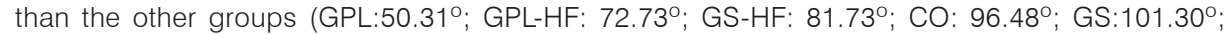
$p=0.001)$. GPL-HF presented a significant higher roughness (Ra/Rq: 2658.0/3367.0 $\eta \mathrm{m} ; \mathrm{p}=0.001)$ than the other groups (GPL: 872.1/1162.0 $\eta$ m; GS-HF: 383.0/603.6 $\eta \mathrm{m}$; GS: 303.4/391.3 $\eta \mathrm{m}$; CO: 263.4/339.1 $\eta \mathrm{m})$. The X-ray diffraction analysis just tetragonal phase in all groups. EDS and SEM analysis show a highest amount of silica on GPL and GPL-HF surface.

CONCLUSION: the application of the low-fusing porcelain glaze by the powder/liquid technique followed by the HF etching promoted a better surface to micromechanical and chemical adhesion.
\end{abstract}

Keywords: zirconia ceramics; nanofilm; surface treatment.

\section{Qual técnica de aplicação de glaze de baixa fusão é melhor para criar uma superfície vítrea sobre a cerâmica Y-TZP?}

\section{RESUMO}

OBJETIVO: Avaliar a influência de dois tipos de aplicação de glaze de baixa fusão na superfície de uma cerâmica de zircônia estabilizada por ítrio (Y-TZP)

METODOLOGIA: Os espécimes de Y-TZP foram divididos em cinco grupos $(n=5)$ de acordo com os tratamentos de superfície: controle (CO), nenhum tratamento foi realizado; aplicação de uma fina camada de glaze de baixa fusão pela técnica de pó/líquido (GPL); GPL seguida por condicinamento com ácido fluorídrico 10\% (HF) (GPL-HF); aplicação de glaze spray (GS); GS seguido condicinamento com HF (GS-HF). Análise do ângulo de contato, aferição de rugosidade, difração de raios X, espectroscopia dispersiva de energia (EDS) e microscópio eletrônico de varredura (SEM) foram realizados.

RESULTADOS: Os exames ANOVA e Tukey revelaram que a GPL apresentou valores de ângulo de contato significativamente menores que os demais grupos (GPL: 50,310; GPL-HF: $72,73^{\circ}$; GS-HF: $81,73^{\circ}$; CO: 96,48; GS: $101,30^{\circ} ; p=0,001$ ). GPL-HF apresentou uma rugosidade significativamente maior (Ra/Rq: 2658.0/3367.0 $\eta$ m;

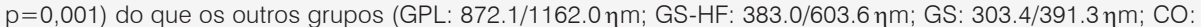
263.4/339.1 $\mathrm{\eta m}$ ). A análise de difracção de raios $X$ apenas a fase tetragonal em todos os grupos. A análise EDS e SEM mostra uma quantidade grande de sílica na superfície GPL e GPL-HF.

CONCLUSÃO: A aplicação do glaze pela técnica de pó/líquido seguida do condicionamento com HF promoveu uma melhor superfície para a adesão micromecânica e química.

Palavras-chave: cerâmica de zircônia; nanofilme; tratamento de superfície. a PhD student in Dental Prosthesis at the Institute of Science and Technology - State University of São Paulo Julio de Mesquita Filho (UNESP), São José dos Campos, SP, Brazil

${ }^{\mathrm{b}}$ Master in Dental Clinic; Federal University (UFJF) Juiz de Fora, MG, Brazil

${ }^{c}$ PhD in Dental Prothesis; Professor at the Braz Cubas Dental University, Mogi das Cruzes, SP, Brazil ${ }^{\mathrm{d}} \mathrm{PhD}$ in Dental Prothesis, Professor at the Federal University of Rio Grande do Norte (UFRN), Natal, RN, Brazil

${ }^{e} \mathrm{PhD}$ in Materials Engineering; Associate of the Sensors and Materials Laboratory at the Center of Special Technologies of the National Institute of Space Research (INPE), São José dos Campos, SP, Brazil

f PhD student in Dental Prosthesis, Adjunct Professor in the Department of Restorative Dentistry of the Federal University of Juiz de For a (UFJF), Juiz de Fora, MG, Brazil

\footnotetext{
Correspondence: Jean Soares Miranda jeansoares@msn.com

Received: October 07, 2017 Accepted: May 25, 2018

Conflict of Interests: The authors state that there are no financial and personal conflicts of interest that could have inappropriately influenced their work. 


\section{INTRODUCTION}

The increasing use of zirconia ceramics stabilized by yttrium (Y-TZP) in the dentist's clinics occurs due to its excellent properties such as biocompatibility, high flexural strength and fracture toughness. They can be used to make single crowns or extensive prosthesis [1].

However, the luting process of this crystalline ceramic do not benefits from hydrofluoric acid (HF) etching [2,3]. Therefore, it was necessary to create some different surface treatments options to zirconia, trying to promote micro retentions and/or make the surface chemically reactive to the adhesive system [4]. Some different surface treatment options, such as sandblasting with aluminum oxide particles [5], laser irradiation [6], sandblasting with aluminum oxide coated by silica particles $[7,8]$, the use of metal primers $[5,6,9,10]$ and plasma selective infiltration [8] was tried. However, an efficient and long-lasting luting protocol to zirconia has not yet been established [10].

Some studies have found deleterious effects of sandblasting on the mechanical strength of Y-TZP ceramics [10]. It has been reported the development of micro cracks responsible for catastrophic fractures of the restorations [10]. It was related that sandblasting surface treatment can change the zirconia tetragonal grains to the monoclinic phase, which may be detrimental to the ceramic longevity $[5,10]$.

The metal primers also demonstrated limited because its application did not increased the bond strength of resin cements to zirconia [11]. Thus, some other surface treatment has been proposed for Y-TZP ceramic, as the application of a thin low-fusing porcelain glass layer on the adhesive surface $[12,13]$. Theoretically, this new layer can be selectively conditioned by HF.

There are two ways to proceed this low-fusing porcelain glass layer: by spray or brush (powder/liquid) technical [4]. Regardless of how this application is made on the ceramic surface, they will be fire on a ceramic oven. Studies had shown promising results in adhesion strength of Y-TZP ceramic to resin cement after this glaze layer application and the hydrofluoric acid (HF) etching $[4,13,14]$. After this process, the silane can be applied. This ensures a microretention and a chemically bond, similar to what happens in the glass ceramics adhesion process [2,3,4].

Therefore, the application of this low-fusing porcelain glass layer [4]. Upon such findings, this research evaluated the influence of two different application of low-fusing porcelain glaze on the surface of a Y-TZP ceramic. The null hypothesis were that there would be no difference in the roughness [1], wettability [2] and composition [3] of the zirconia samples that had the application of glaze performed by different comercial techniques.

\section{MATERIALS AND METHODS}

\section{Specimen's preparation}

The materials used in this study, their trademarks, manufacturers, composition and lots are presented in Table 1.

Four Y-TZP zirconia blocs (IPS e.max ${ }^{\circledR}$ ZirCAD, Ivoclar Vivadent, Schaan, Liechtenstein) were cut to a standard size of $15 \times 15 \times 2 \mathrm{~mm}$ with a diamond cutting disc (Extec High Concentration, Enfield - CT, USA) in a precision cutting machine to obtain 20 specimens (IsoMet ${ }^{\circledR} 1000$ Precision Saw, Buehler, Lake Buff-IL, USA). Both sides of the samples were regularized with \#180, \#600 and \#1200 granule sandpaper (Norton Saint - Gobain, São Paulo, Brazil). Prior to sintering, the samples were washed in an ultrasonic bath (Cristófoli Ultrasonic Washer, Campo Mourão, Paraná, Brazil) in isopropyl alcohol for eight minutes [13]. The sintering was carried out in a Zyrcomat T oven (VITA, Zahnfabrick, Germany) up to the temperature of $1530^{\circ} \mathrm{C}$. After this process, the final samples dimensions were $12 \times 12 \times 1.5 \mathrm{~mm}$.

The specimens were randomly divided into five groups $(\mathrm{n}=5)$ according the surface treatments: control $(\mathrm{CO})$, in which no surface treatment was performed; application of a thin low-fusing porcelain glass layer by the conventional powder/liquid (GPL) technique; application of low melt glaze by the conventional technique followed by HF etching (GPL-HF); application of glaze spray (GS); and application of glaze spray followed by HF etching (GS-HF).

In the GS groups the Glaze Spray VITA AKZENT Plus (Vita Zahnfabrik) was applied at a standard distance of $3 \mathrm{~cm}$ from the ceramic, taking the time required for the surface to be completely covered. To the GPL groups the VITA AKZENT Glaze (Vita Zahnfabrik, bad säckingen, Germany) was made mixing eight drops of the liquid to $0.2 \mathrm{~g}$ of the glaze powder with a glass spatula, until a creamy consistency was reached. Then, it was applied on the ceramic surface

Table 1. Commercial brand, use, manufacturer, composition and lot of materials used in the research.

\begin{tabular}{|c|c|c|c|c|}
\hline Brand & Material Type & Manufacturer & Composition & Lot \\
\hline IPS e.max ${ }^{\circledR}$ ZirCAD & Y-TZP ceramic & Ivoclar-Vivadent, Schaan, Liechtenstein & $\begin{array}{l}\mathrm{ZrO} 2+\mathrm{HfO}_{2}\left(94.4 \text { wt\%), } \mathrm{Y}_{2} \mathrm{O}_{3}(5.2 w t \%)\right. \\
\mathrm{Al}_{2} \mathrm{O}_{3}(0.2-0.5 \text { wt\%) }\end{array}$ & M24091 \\
\hline VITA Akzent ${ }^{\circledR}$ Plus & Glaze Spray & Vita Zanhfabrik, Bad Sachingen, Germany & 111-29-5 pentano-1,5-diol & A0764 \\
\hline VITA Akzent ${ }^{\circledR}$ & Glaze powder / liquid & Vita Zanhfabrik, Bad Sachingen, Germany & 111-29-5 pentano-1,5-diol & $\begin{array}{l}21740 \\
22601\end{array}$ \\
\hline Condac Porcelana & Hydrofluoric acid & FGM, Pinheiros, SP, Brazil & $\begin{array}{l}10 \% \text { HF, water, thickener, surfactant } \\
\text { and colorant }\end{array}$ & 250215 \\
\hline
\end{tabular}


using a brush. All the glazed samples were taken to a VITA VACUMAT 6000 MP oven (VITA, Zahnfabrik, Germany) for the glaze firing process according to the manufacturer's guidelines (starting at $500^{\circ} \mathrm{C}$, then raised at $80^{\circ} \mathrm{C} / \mathrm{min}$ to $900^{\circ} \mathrm{C}$, maintaining this temperature for $1 \mathrm{~min}$ ). The GS$\mathrm{HF}$ and the GPL-HF groups received an additional 10\% HF etching treatment (Contac Porcelana 10\%, Dentsply, Petrópolis, Rio de Janeiro, Brazil) for $60 \mathrm{~s}$ and then was washed with air-water spray for twice the HF etching time. The blocks were then cleaned again in sonic bath (Cristófoli Ultrasonic Washer) for $5 \mathrm{~min}$ in distilled water to remove the acid precipitate.

\section{Contact angle}

For contact angle analysis, three specimens from each group were used after receiving the surface treatment. The contact angle was measured by a goniometer (Ramé HartInc, 100-00-115, Mountain Lakes, New Jersey, USA) in a controlled-temperature environment. The goniometer was connected to a computer equipped with specific software (RHI 2001 Imaging Software), and the sessile drop technique was used. A drop of distilled water was placed on the ceramic surface by means of a syringe, and the contact angle was measured for $10 \mathrm{~s}$ (30 frames per second). Tree measurements were performed for each disc, totaling 12 measurements per group.

\section{Surface topography}

Roughness measurements on the different surfaces were carried out with a profilometer (Wyko NT 1100, Veeco, Somerset, New Jersey,USA) in all five specimens of each group. Roughness ( $\mathrm{Ra}$ and $\mathrm{Rq}$ ) was measured four times in each specimen at a distance of $1.6 \mathrm{~mm}$ with a speed of $0.05 \mathrm{~mm} / \mathrm{s} 3 \mathrm{D}$ imagens of the specimens surface was also obtained (Figure 1).

Statistical analysis was performed with MiniTab 16 software (MiniTab Inc., State College, PA, USA). Mean and standard deviation (SD) values of contact angle and surface roughness were analyzed with 1-way ANOVA and Tukey's test; $p$ values less than 0.05 were considered statistically significant.

\section{X-ray diffraction}

X-ray diffraction (Model X'pert Powder, PANalytical, Almelo, Netherlands) was performed in one sample of each group with the database software X'Pert High Score (PANalytical) to visualize the crystallization pattern and the zirconia phase on the different groups.

\section{Energy-dispersive spectroscopy (EDS) and scanning electron microscopy (SEM)}

One specimen of each group was sputter-coated with gold-palladium alloy prior to be examined in a scanning electron microscope with a high-resolution emission field (Magellan 400 L, FEI Company, Brno, Czech Republic. The chemical analysis of the constituents was performed by EDS (Bruker Nano GmbH, Berlin,Germany).

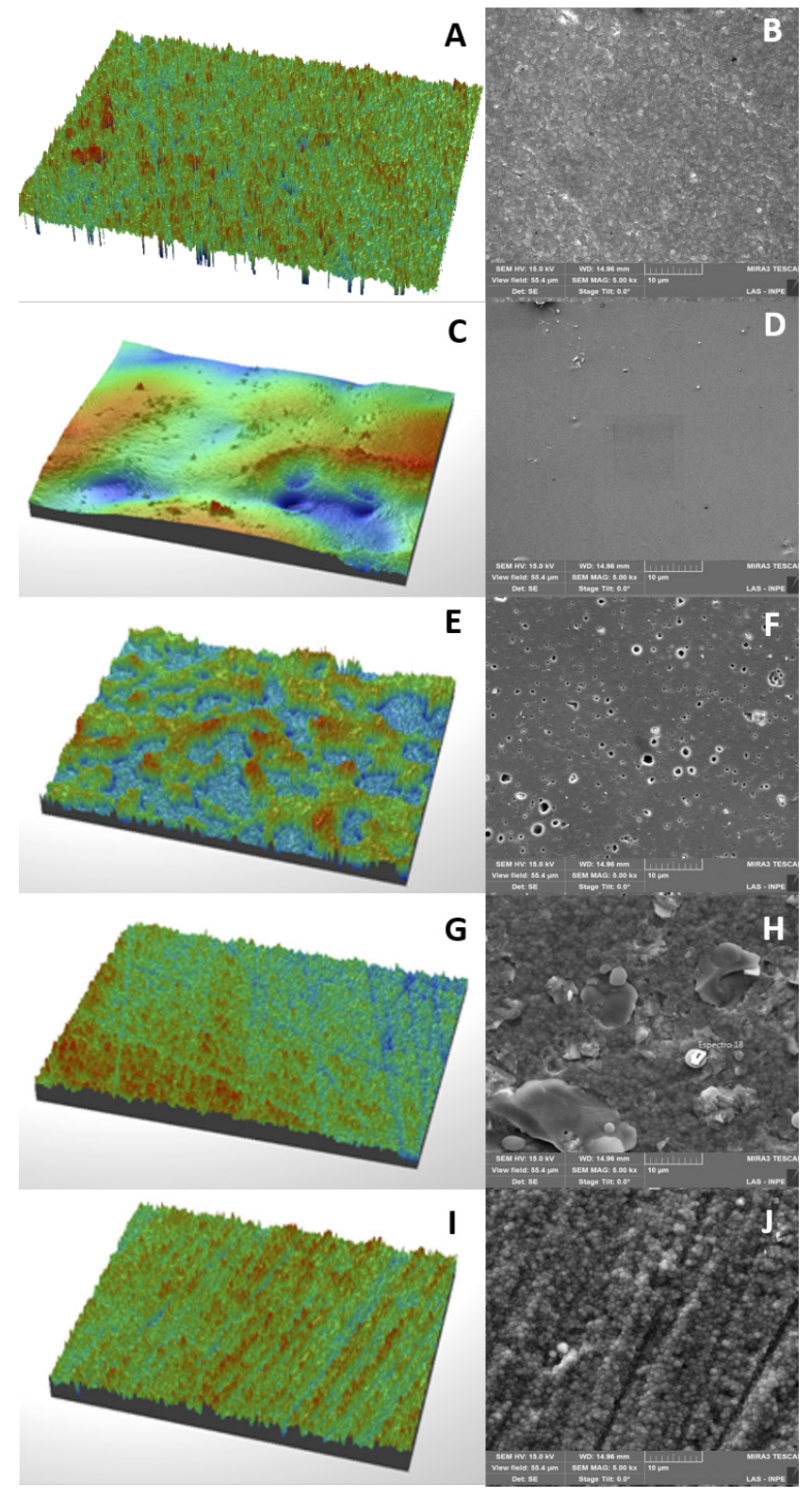

Figure 1. A-J - Micrographs (5000x) and 3D images of the surface roughness after the surface treatments: A, B - CO; C, D - GPL; E, F - GPL-HF; G, H - GS; I, J - GS-HF. The images suggest that the application of the low-fusing porcelain glass was more effective when using the powder/liquid method, when compared to the spray. The hydrofluoric acid etching removed part of the layer from the GPL-HF sample, which may favor a micromechanical retention of the luting material. However, GS-HF sample hah almost no vitreous substance remaining on the surface, this sample presented predominantly zirconia.

\section{RESULTS}

\section{Surface Energy Measurement}

The ANOVA and Tukey tests revealed a statistical difference between the groups $(\mathrm{p}=0.001)$. The GPL group had significantly lower contact angle values than the other groups, which consequently generated higher values of 
surface energy. This group was followed by GPL-HF, which obtained wettability results similar to GS-HF. However, the GS treatment did not show a significant difference when compared to the CO group (Table 2).

\section{Surface topography analysis}

For roughness statistical analysis was performed multiple comparison test of Tukey (Table 2). This test showed that for both roughness, $\mathrm{Ra}$ and $\mathrm{Rq}$, the only statistically different group that was GPL-HF. This one presented the highest roughness $(p=0.001)$. However, the other groups did not show statistical difference when compared to the untreated group (CO) (Figure 1).

\section{X-ray Diffraction Analysis}

The X-ray diffraction analysis revealed that the low fusing glass layer application and the heat treatment of this new layer did not alter zirconia structure that showed only the tetragonal and no monoclinic phase in all groups (Figure 2).

\section{EDS and SEM}

It was observed, by EDS analysis, that the GPL-HF group presented the highest amount of vitreous content on its surface, followed by GPL and GS-HF, differently CO group, which could not only contain only the composition Y-TPZ zirconia, as expected (Table 3 ).

Table 2. Results of the wettability and perfilometry tests indicating a significant difference between the contact angles and the roughness of the different experimental groups.

\begin{tabular}{lcccc}
\hline & $\begin{array}{c}\text { Contact Angle (SD) } \\
\left({ }^{\circ}\right)\end{array}$ & $\begin{array}{c}\text { Surface Energy } \\
(\mathrm{mN} / \mathrm{m})\end{array}$ & $\begin{array}{c}\text { Ra (SD) } \\
(\eta \mathrm{m})\end{array}$ & $\begin{array}{c}\text { Rq (SD) } \\
(\eta \mathrm{m})\end{array}$ \\
CO & $96.48(6.34)^{\mathrm{a}}$ & 25.24 & $263.4(11.0)^{\mathrm{a}}$ & $339.1(12.75)^{\mathrm{a}}$ \\
GPL & $50.31(3.97)^{\mathrm{c}}$ & 53.58 & $872.1(224.3)^{\mathrm{a}}$ & $1162.0(275.1)^{\mathrm{a}}$ \\
GPL-HF & $72.73(11.18)^{\mathrm{b}}$ & 39.99 & $2658.0(1476.0)^{\mathrm{b}}$ & $3367.0(1802.0)^{\mathrm{b}}$ \\
GS & $101.3(2.86)^{\mathrm{a}}$ & 22.28 & $303.4(31.9)^{\mathrm{a}}$ & $391.3(45.73)^{\mathrm{a}}$ \\
GS-HF & $81.73(7.32)^{\mathrm{b}}$ & 34.38 & $383.0(78.1)^{\mathrm{a}}$ & $603.6(276.1)^{\mathrm{a}}$ \\
\hline
\end{tabular}

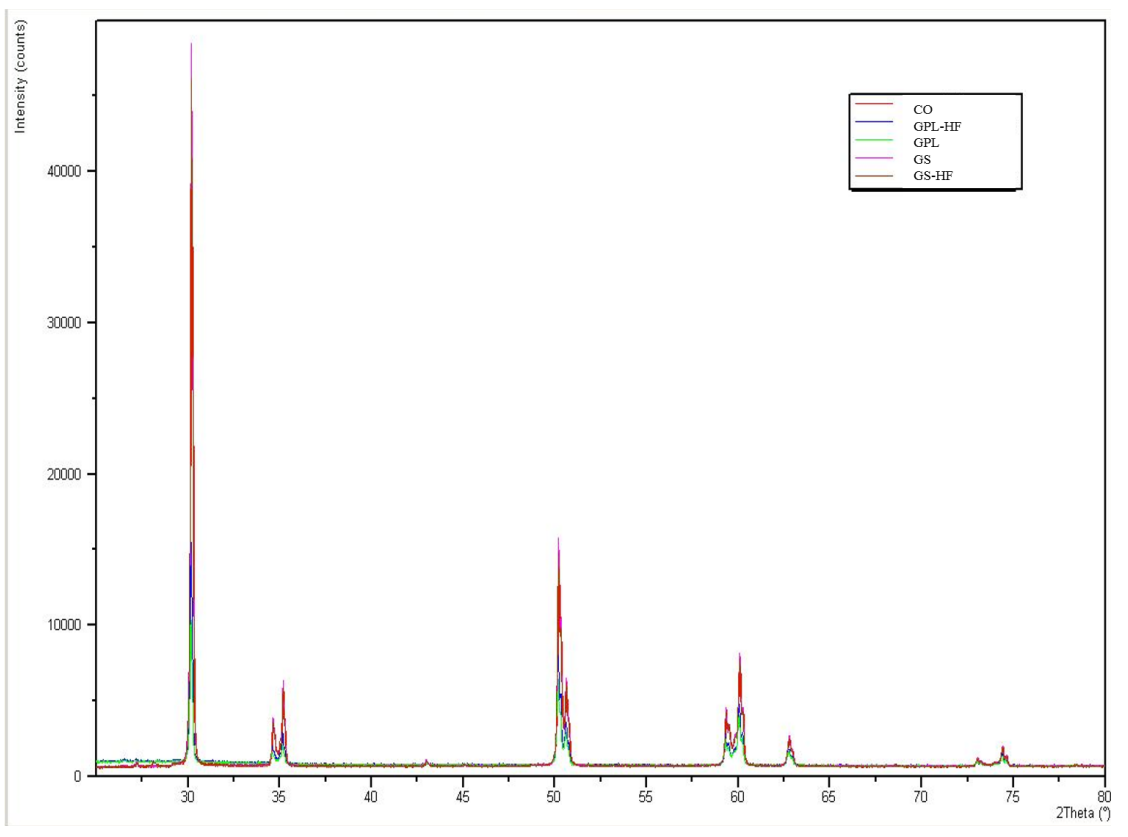

Figure 2. No specimen showed monoclinic peaks, only tetragonal, indicating that was no phase transformation in the Y-TZP zirconia after the heat treatment required by the low-fusing porcelain glass.

Table 3. Percentage of each element found in the samples of groups analyzed by EDS.

\begin{tabular}{lcccccccc}
\hline & $\mathrm{Y}(\%)$ & $\mathrm{Ca}(\%)$ & $\mathrm{Ba}(\%)$ & $\mathrm{K}(\%)$ & $\mathrm{Na}(\%)$ & $\mathrm{O}(\%)$ & $\mathrm{Si}(\%)$ & $\mathrm{Zr}(\%)$ \\
CO & 4,1 & & & & & & & \\
GPL & & 5,4 & 2,2 & 3,6 & 4,7 & 39,2 & 40,7 & \\
GPL-HF & & 5,7 & 2,4 & 3,8 & 5,1 & 40,1 & 43 & \\
GS & 4,2 & & & & & 15,16 & & 80,1 \\
GS-HF & & 0,4 & & 0,3 & 0,7 & 30,8 & 2,7 \\
\hline
\end{tabular}


Microscopy images corroborate these findings and reveal the amount of glaze on the zirconia surface after application of this low fusion glass and after HF etching. It is observed that the application of the thin layer of low-fusing porcelain glass is more homogeneous when applied by the powder/liquid technique. When the glaze spray was used, the deposition is more scarce and irregular. It was also possible to observe in the GS-HF group that the glaze was almost completely removed from the zirconia surface after HF etching, different from the GPL-HF, where it was observed the formation of tags for micro-mechanical adhesion (Figure 1).

\section{DISCUSSION}

Although zirconia for dentistry may contain until $15 \%$ silica or other glasses, becoming very dense and homogeneous on sintering [15], conventional adhesive procedures could not succeed [16] because this ceramic is not etched by HF. Therefore, some studies have attempted to perform different treatments to achieve this bond between zirconia and resin cement $[1,17,18,19,20]$. A well-reported treatment is the application of a thin layer of low-fusing porcelain glaze on the zirconia surface $[1,4,13,21,22,23]$. This material is composed by vitreous porcelain (high silica content, amorphous matrix or $\mathrm{SiO}_{2}$ ) and pigments (metallic oxides), making a zirconia glazed surface etchable by HF $[23,24]$. In the current study two strategies to apply the low-fusing porcelain glaze was used: a spray (GS - VITA Akzent Spray Glaze) and a powder + liquid (GPL - VITA Akzent Spray Glaze) application. Both glazes was made by the same manufacturer and had similar chemical compositions, but with different modes of application. It was also carried out the HF etching of this layer to characterize each situation.

The null hypothesis was rejected by the data obtained in this research. The first one was that there would be no difference in the surface roughness of the groups after the surface treatments. However $\mathrm{Ra}$ and $\mathrm{Rq}$ presented significantly higher values in the GPL-HF group (Table 2). This result is similar to that found in others studies when using this same glaze $[1,4,21]$. Roughness increase is due to HF etching that creates micromorphological changes and can optimize the interaction between the adhesive and substrate via micromechanical retention $[1,4,13,23]$. According to some authors $[1,4]$, this micromechanical retention is more favorable for adhesion of the luting material to the Y-TZP than the chemical bond that is created due the increase of silica on the treated surface.

With SEM analysis, it is possible to observe that the surface treatment promoted topographic alteration of the GPL-HF when compared to GPL. This is directly related to HF etching that led to higher roughness. However, this difference in the Y-TZP ceramic surface is not observed when comparing GS and GS-HF groups (Figure 1). This probably happened because the deposition of the glaze spray does not appear to be uniform and is possibly further removed by HF etching, obtaining a topography more similar to the group CO. What would also explain why in studies of bond strength which used glaze spray adhesion was not satisfactory $[4,22]$, unlike the use of glaze by the powder liquid technique that resulted in a greater bond strength [4].

Opposite to the suggested by the second null hypothesis, it was possible to note a difference in the wettability of the specimens from the different groups. The highest wettability was found in the GPL (53.58) group, followed by GPL-HF (39.99) and GS-HF (34.38) (Table 2). However, a greater result to GPL group is in disagreement with Bottino et al. (2015) [2], who said that the HF etching increase the ceramics surface energy, increasing their adhesive potential. The result of this research is a reflection of the contact angles data, because the smaller the contact angle (GPL: $50.31^{\circ}$; GPL-HF: 72.73; GS-HS: 81.73) the greater the wettability and the surface energy, which suggest to an improvement in the of adhesion process [1].

As for the composition of the specimens, it was also possible to notice a difference in the chemical content of the different groups. So this third null hypothesis was also rejected. In the CO, GS and GS-HF groups, a predominance of zirconia was found. In the GPL and GPL-HF groups it was notice a significant amount of silica on the surface (Table 3 ). This situation seems to be more favorable since the increased percentage of silica on the surface may contribute to an enhanced physical and chemical interaction between the glass film $\mid$ silane $\backslash$ resin cement and permit a better bond [4]

Another favorable factor to the low-fusing porcelain glaze application is that after this surface treatment no monoclinic peak was found in the zirconia independent of the technique. Only Y-TZP in its tetragonal stability phase was observed (Figure 2). What makes this an advantage since the literature suggests that sandblasting with aluminum oxide initiate the effects of $t-m$ transformation occurs at superficial grains on the ceramic surface, leading to volume increase at a localized area around the superficial defects $[1,21,25]$. However, after that, $t-m$ phase transformation spreads throughout the material surface and subsurface, resulting in grain pullout and an increase in roughness, jeopardizing strength, fracture toughness and density of Y-TZP structures $[21,25]$.

However, this in vitro research has some limitations such as the absence of the adhesion tests for these different surface treatments; and measurement of the glaze layer thickness, since the literature relates between $12 \mu \mathrm{m}$ [3] and $120 \mu \mathrm{m}$ (POZZOBON et al., 2017) [21]. Vanderlei, Bottino e Valandro (2014) [4] considered that the clinically recommended maximum misfit is around $120 \mu \mathrm{m}$, so this glaze layer would not affect internal adaptation of the crowns that should be be carefully controlled and compensated by the $\mathrm{CAD} / \mathrm{CAM}$ technique when designing and milling the restorations $[4,22]$.

In agreement with other researches, that evaluated the effect of the low-fusing porcelain glaze application by the powder + liquid technique followed by the HF etching on the Y-TZP ceramic surface with different analysis $[1,4$, $13,21,23]$, it is possible to conclude that this surface 
treatment is more favorable to adhesive luting than the other surface treatments tested by our research. In the present research, it was found that the GPL-HF treatment modifies the roughness, the wettability, deposited a silica content on the zirconia surface, it have higher standardization of the glaze layer and does not generate t-m phase transformation.

\section{CONCLUSION}

Among the treatments performed, the application of the low-fusing porcelain glaze application by the powder + liquid technique followed by the HF etching suggest a better surface to micromechanical and chemical adhesion due to the greater roughness and the amount of silica on the Y-TZP ceramic.

\section{REFERENCES}

1. Moradabadi A, Roudsari SE, Yekta BE, Rahbar N. Effects of surface treatment on bond strength between dental resin agent and zirconia ceramic. Mater Sci Eng C Mater Biol Appl. 2014;34:311-7. https://doi. org/10.1016/j.msec.2013.09.015

2. Bottino MA, Snellaert A, Bergoli CD, Özcan M, Bottino MC, Valandro LF. Effect of ceramic etching protocols on resin bond strength to a feldspar ceramic. OperDent. 2015;40:40-6. https://doi.org/10.2341/13-344-L

3. Bottino MA, Bergoli C, Lima EG, Marocho SM, Souza RO, Valandro LF. Bonding of Y-TZP to dentin: effects of Y-TZP surface conditioning, resin cement type, and aging. Oper Dent. 2014;39:291-300. https://doi. org/10.2341/12-235-L

4. Vanderlei A, Bottino MA, Valandro LF. Evaluation of resin bond strength to yttria-stabilized tetragonal zirconia and framework marginal fit: comparison of different surface conditionings. Oper Dent. 2014;39:50-63. https://doi. org/10.2341/12-269-L

5. Amaral M, Belli R, Cesar PF, Valandro LF, Petschelt A, Lohbauer U. The potential of novel primers and universal adhesives to bond to zirconia. J Dent. 2014;42:90-8. https://doi.org/10.1016/j.jdent.2013.11.004

6. Dias de Souza GM, Thompson VP, Braga RR. Effect of metal primers on microtensile bond strength between zirconia and resin cements. J Prosthet Dent. 2011;105:296-303. https://doi.org/10.1016/S0022-3913(11)60055-3

7. Cavalcanti AN, Foxton RM, Watson TF, Oliveira MT, Giannini M, Marchi GM. Y-TZP ceramics: key concepts for clinical application. Oper Dent. 2009;34:344-51. https://doi.org/10.2341/08-79

8. Papia E, Zethraeus J, Ransbäck PÅ, Wennerberg A, Vult von Steyern P. Impaction-modified densely sintered yttria-stabilized tetragonal zirconium dioxide: methodology, surface structure, and bond strength. J Biomed Mater Res B Appl Biomater. 2012;100:677-84. https://doi.org/10.1002/ jbm.b.31992

9. Maeda FA, Bello-Silva MS, de Paula Eduardo C, Miranda Junior WG, Cesar PF. Association of different primers and resin cements for adhesive bonding to zirconia ceramics. J Adhes Dent. 2014;16:261-5.

10. Özcan M, Bernasconi M. Adhesion to zirconia used for dental restorations: a systematic review and meta-analysis. J Adhes Dent. 2015;17:7-26.
11. Aboushelib MN, Mirmohamadi $H$, Matinlinna JP, Kukk E, Ounsi HF, Salameh Z. Innovations in bonding to zirconia-based materials. Part II: Focusing on chemical interactions. Dent Mater. 2009;25:989-93. https:// doi.org/10.1016/j.dental.2009.02.011

12. Pereira LL, Campos F, Dal Piva AM, Gondim LD, Souza RO, Özcan M. Can application of universal primers alone be a substitute for airborne-particle abrasion to improve adhesion of resin cement to zirconia? J Adhes Dent. 2015;17:169-74

13. Yamamoto LT, Rodrigues VA, Dornelles LS, Bottino MA, Valandro LF, Melo RM. Low-Fusing Porcelain Glaze Application on 3Y-TZP Surfaces can Enhance Zirconia-Porcelain Adhesion. Braz Dent J. 2016;27:543-7. https:// doi.org/10.1590/0103-6440201601014

14. Antunes MCF, Miranda JS, Carvalho RAL, Carvalho RF, Kimpara ET, Souza ROA, Leite FPP. Can low-fusing glass application affect the marginal misfit and bond strength of Y-TZP crowns? Braz oral res 2018;32:1-10. https:// doi.org/10.1590/1807-3107bor-2018.vol32.0034

15. Kelly JR. Dental ceramics: what is this stuff anyway? J AmDent Assoc 2008;139:4-7. https://doi.org/10.14219/jada.archive.2008.0359

16. Thompson JY, Stoner BR, Piascik JR, Smith R.Adhesion/cementation to zirconia and other non-silicateceramics: where are we now? Dent Mater 2011;27:71-82. https://doi.org/10.1016/j.dental.2010.10.022

17. Gargava S, Ram SM. Evaluation of Surface Conditioning of Zirconia and Its Effect on Bonding to Resin-Luting Agent. Journal of Contemporary Dentistry 2013; 3:7-10. https://doi.org/10.5005/jp-journals-10031-1026

18. Inokoshi M, Kameyama A, De Munck J, Minakuchi S, Van Meerbeek B. Durable bonding to mechanically and/or chemically pre-treated dental zirconia. J Dent. 2013;41:170-9. https://doi.org/10.1016/j. jdent.2012.10.017

19. Martins AR, Gotti VB, Shimano MM, Borges GA, Gonçalves Lde S. Improving adhesion between luting cement and zirconia-based ceramic with an alternative surface treatment. Braz Oral Res. 2015;29:1-2. https:// doi.org/10.1590/1807-3107BOR-2015.vol29.0054

20. Usumez A, Hamdemirci N, Koroglu BY, Simsek I, Parlar O, Sari T. Bond strength of resin cement to zirconia ceramic with different surface treatments. Lasers Med Sci. 2013;28:259-66. https://doi.org/10.1007/ s10103-012-1136-X

21. Pozzobon JL, Pereira GKR, Wandscher VF, Dorneles LS, Valandro LF. Mechanical behavior of yttria-stabilized tetragonal zirconia polycrystalline ceramic after different zirconia surface treatments. Mater Sci Eng C Mater Biol Appl. 2017;77:828-35. https://doi.org/10.1016/j.msec.2017.03.299

22. Şanlı S, Çömlekoğlu MD, Çömlekoğlu E, Sonugelen M, Pamir T, Darvell BW. Influence of surface treatment on the resin-bonding of zirconia. Dent Mater. 2015;31:657-68. https://doi.org/10.1016/j.dental.2015.03.004

23. Wandscher VF, Prochnow C, Rippe MP, Dorneles LS, Callegari GL, Baldissara P, Scotti R, Valandro LF. Retentive Strength of Y-TZP Crowns: Comparison of Different Silica Coating Methods on the Intaglio Surfaces. Oper Dent. 2017;42:121-33. https://doi.org/10.2341/16-090-L

24. Ntala P, Chen X, Niggli J, Cattell M. Development and testing of multiphase glazes for adhesive bonding to zirconia substrates. J Dent. 2010 Oct;38:773-81. https://doi.org/10.1016/j.jdent.2010.06.008

25. Mota YA, Cotes C, Carvalho RF, Machado JPB, Leite FPP, Souza ROA, Özcan M. Monoclinic phase transformation and mechanical durability of zirconia ceramic after fatigue and autoclave aging. J Biomed Mater Res B Appl Biomater. 2017;105:1972-7. https://doi.org/10.1002/jbm.b.33720 